\title{
М.М. Сенявин и оптимизация ионообменных процессов на основе математического моделирования
}

\author{
Комарова И.В., Галкина Н.К. \\ Институт геохимии и аналитической химии им. В.И. Вернадского Российской Академии наук, \\ Москва
}

Поступила в редакцию 25.11.2017 г.

\begin{abstract}
Целью настоящей статьи являлось изложение подходов к оптимизации промышленных ионообменных процессов на основе математического моделирования и основных результатов разработок, выполненных под руководством М.М. Сенявина в лаборатории сорбционных методов ГЕОХИ РАН примененных в водоподготовке. М.М.Сенявин предложил и реализовал физико-химический подход, при котором решались фундаментальные научные задачи, направленные на количественное описание крупномасштабных ионообменных процессов. С целью разработки методологии исследования в качестве базового объекта были выбраны типовые процессы ионообменного обессоливания воды, которые представляют динамику массобмена в многокомпонентной системе и широко применяются в промышленности.

В статье изложены основные составляющие подхода, заключающиеся в разработке математических моделей отдельных стадий ионообменного процесса, экспериментальном определении коэффициентов математической модели, накоплении коэффициентов моделей для различных сорбентов, создании банка данных, изучении конкретных технологических процессов методом вычислительного эксперимента, создании программ расчета отдельных фильтрующих аппаратов и целых технологических комплексов, а также нахождении оптимальных условий процесса. В настоящее время в лаборатории сорбционных методов работы по моделированию и оптимизации ионообменных процессов продолжают развиваться
\end{abstract}

Ключевые слова: М.М. Сенявин, ионообменные процессы, оптимизация, математическое моделирование.

\section{M.M. Senyavin and ion-exchange optimization based on mathematic modeling}

\author{
Komarova I.V., Galkina N.K. \\ Vernadsky Institute of Geochemistry and Analytical Chemistry of Russian Academy of Sciences \\ (GEOKHI RAS). Moscow
}

The article is devoted to the description of approaches to mathematical model based optimization of industrial ion-exchange (IEX) processes for water preparing, focusing to main results of developments which have been chaired by M. M. Senyavin in the Laboratory of sorption processes in the Vernadsky Institute of Russian Academy of Sciences (GEOKHI RAS).

M. M. Senyavin has proposed and implemented a physic-chemical approach based on the solution of fundamental tasks directed to the quantitative description of large-scale ion-exchange processes.

For elaboration of the investigation methodology, typical processes of water desalination representing the dynamics of mass-exchange in multi-component systems have been chosen.

The main distinctions of the approach for IEX optimization are presented in the article, and they consist of studies: the development of mathematical models of main stages of process, experimental collection of model coefficients for different sorbents and the creation of data-bank, development of computer pro- 
grams, study of separate technological processes by method of digital experiment, computation and finding the optimal parameters for separate apparatuses and complete technological schemes. Currently, studies on physic-chemical optimization are continued of the Laboratory

Keywords: M. M. Senyavin, ion-exchange processes, optimization, mathematical modeling

\section{Введение}

Ионообменные процессы приобретают все большее значение во многих областях современной промышленности. Расширяются масштабы традиционного ионообменного получения обессоленной воды и повышаются требования к степени ее деминерализации со стороны энергетики, химической, полупроводниковой, электронной и целлюлозно-бумажной промышленности. Все шире применяется ионный обмен для получения металлов. Особое значение приобретают в последние годы ионообменные процессы в решении проблемы охраны окружающей среды от загрязнений: очистка сточных вод, организации оборотного водоснабжения.

Наиболее крупномасштабным является применение ионитов для обессоливания воды в промышленных целях, главным образом на тепловых и атомных электростанциях. В современных условиях для обеспечения технологической эффективности и экономической целесообразности промышленной водоподготовки нельзя обойтись без оптимизации сложных ионообменных процессов. Сегодня оптимизация необходима также для проектирования и для проведения пуско-наладочных работ при запуске новых цехов ионообменной водоподготовки, а также в ходе их эксплуатации.

Существует два основных подхода к оптимизации промышленных ионообменных процессов: один из них можно назвать эмпирическим или полуимперическим, и он основан на составлении т.н. « технологических карт», а именно библиотеки экспериментальных зависимостей выходных характеристик процессов водоподготовки от варьируемых параметров.

В практике водоподготовки при проектировании и эксплуатации установок по обессоливанию и умягчению воды используются экспериментальные значения динамической обменной емкости ионитов, полученные при определенных условиях. Выбор числа ступеней очистки, типа ионитов, размеров фильтров, высоты загрузки ионитов и режимов регенерации осуществляется на основе эмпирических формул, зависимостей и коэффициентов, полученных экспериментально. Разработаны методики расчета, полученные результаты уточняются в процессе наладки и длительной эксплуатации ионообменных установок. Оптимизация процесса проводится на основе экспериментальных зависимостей. В Харьковском отделении Института Теплоэлектропроект была разработана программа оптимизации, использующая зависимости рабочей обменной емкости от условий работы установки. Фирма Room and Haas представляет программное обеспечение для оптимизации процессов водоподготовки, в котором в качестве модели используются уравнения регрессии, аппроксимирующие экспериментальные зависимости рабочей обменной емкости от параметров опыта

Другой подход к оптимизации является физико-химическим, в его развитии важную роль сыграл М.М. Сенявин, который считал необходимым ставить и решать фундаментальные научные задачи, направленные на решение крупномасштабных ионообменных процессов.

В лаборатории сорбционных методов ГЕОХИ РАН под руководством М.М.Сенявина в течение многих лет проводились работы по изучению физикохимических закономерностей ионного обмена на сорбентах разных типов, решен ряд 
задач динамики сорбции[1-5]. На этой основе созданы математические модели различных сорбционных процессов, разработаны методы оптимизации, которые реализованы в виде программ для ЭВМ, что составляет научную базу решения ионообменных задач разной степени сложности[6-12]. Таким способом были изучены многоступенчатые и многостадийные ионообменные процессы обессоливания воды и очистки конденсата в промышленных установках на ТЭС и АЭС.

Работы по математическому моделированию были начаты в группе М.М.Сенявина в пятидесятые годы еще до создания лаборатории сорбционных методов.

На первой конференции по ионному обмену, состоявшейся в 1961 году, был представлен доклад Сенявина М.М., Галкиной Н.К., Рубинштейна Р.Н. [7], положивший начало работам по моделированию и оптимизации ионообменных процессов. Уже в те годы, когда вычислительные машины были редкостью, Сенявин М.М. начал активно развивать в лаборатории сорбционных методов ГЕОХИ расчетные методы, направленные в основном на решение практических задач. Когда вычислительные машины стали доступны, появилась возможность расчета динамики ионного обмена в многокомпонентной системе. В качестве базового объекта с целью разработки методологии исследования был выбран типовой процесс ионообменного обессоливания воды, который представляет собой динамический процесс в многокомпонентной системе и широко применяется в промышленности.. Математическая модель позволяет учитывать поведение каждого компонента в твердой и жидкой фазах на разных стадиях процесса, слабую ионизацию ионообменных групп катионитов и анионитов, природу анионов при катионном и анионном обмене и гидродинамическое перемешивание в пространстве между зернами и в пространстве над слоем ионита во время регенерации и отмывки.

Получение ионообменным методом очищенной воды из природной, представляющей собой раствор смеси катионов натрия, калия, магния и кальция и анионов соляной, серной, угольной и кремневой кислот, - сложный процесс, реализуемый в виде многоступенчатых схем, а в каждом отдельном фильтре схемы - в несколько чередующихся стадий: сорбция на исходной форме сорбента, взрыхление, регенерация отработанного сорбента, отмывка от избытка регенерирующего раствора, повторная сорбция на частично регенерированном сорбенте в цикле до стабилизации.

По мере развития вычислительной техники разработанные в лаборатории Сенявина М.М. математические модели сорбционных процессов постепенно усложнялись $[6,10,11,14,16]$, была доказана их адекватность сопоставлением с экспериментом для установок различного размера, в том числе и промышленных фильтров, проводилась работа по созданию методологии, разработке новых методов определения параметров и расширению объектов исследования.

В качестве математической модели динамики многокомпонентного ионообменного процесса был принят послойный метод расчета, в котором в качестве уравнения материального баланса используется конечно-разностный аналог дифференциального уравнения, а из уравнений кинетики рассчитываются шаги счета по времени и по высоте фильтра. Учитываются гидродинамическое перемешивание раствора между зернами в слое и над слоем ионита, слабая ионизация обменных групп катионитов и анионитов и двухступенчатая диссоциация слабых кислот при катионном и анионном обмене $[8,10,11]$

Создание в течение многих лет научного фундамента в виде математических моделей и программ, а также банка равновесных и кинетических характеристик, 
обеспечило реальную возможность изучения разнообразных конкретных технологических процессов в том числе ионообменного обессоливания воды и очистки сточных вод методом вычислительного эксперимента, который оказался во многих случаях незаменимым $[9,12,30]$.

На основе математических моделей были рассчитаны зависимости рабочей обменной емкости ионитов от скорости потока,. расхода и концентрации реагента для различных параметров отключения фильтра, представленные в виде Атласа,что позволяет выбрать оптимальное распределение ионных нагрузок между ступенями очистки[23].

Работы по оптимизации начались в 1966 году. Постановка задачи оптимизации осуществлялась на примере процесса деминерализации воды. М.М. Сенявин возглавил это новое направление, которое развивалось и расширялось в течение многих лет и до настоящего времени.

Разработан метод оптимизации впервые примененный к сорбционным процессам, включающий формулировку задачи, обоснованный выбор критериев, создание способа нахождения оптимальных режимов на основе имеющихся математических моделей.

Задача оптимизации процесса ионообменной деионизации воды решалась на основе математической модели и выбранного критерия оптимальности методом наискорейшего спуска на ЭВМ. В качестве критерия оптимальности выбран экономический показатель, позволяющий учесть такие технологические характеристики, как продолжительность рабочего цикла, объем ионита, гидравлическое сопротивление слоя ионита.

Первоначально оптимальные условия находились для одного фильтра, затем для технологических схем $[19,21,25,27]$. Было доказано, что ни по одному из важных параметров процесса в отдельности не существует оптимума. В этой сложной многовариантной задаче, расчленив ее на ряд элементов, были достаточно строго сформулированы взаимосвязи и тем самым не потеряна общность .

Впервые четко рассмотрено единовременное взаимодействие наиболее важных физико-химических и технологических параметров, определяющих экономическую эффективность ионообменного процесса деминерализации воды. Для действующего процесса в качестве критерия оптимальности был выбран расход реагентов на единицу очищенной воды, а для проектирования - приведенные затраты.

Постановка задачи оптимизации: для воды заданного состава и установки заданной производительности при условии получения воды заданного качества необходимо найти оптимальные условия , отвечающие минимальному значению критерия оптимальности. Параметрами оптимизации были скорость потока, высота слоя ионита, концентрация и расход реагента на регенерацию при заданных значениях кинетических и равновесных коэффициентов $[17,18]$.

Более того, М.М. Сенявин считал необходимым определить расчетным путем, какими характеристиками должны были бы обладать оптимальные иониты для водоподготовки, если бы была поставлена задача целенаправленного синтеза. В результате работы было получено, что на первой ступени очистки воды на катионите оптимальное значение константы обмена натрия на водород равно 2, а константы обмена кальция на водород $1.5\left(\mathrm{~cm}^{3} / \mathrm{cm}^{3}\right)^{1 / 2}$. Значение константы обмена натрия для катионита КУ-2 (1.2), для сульфоугля (0.65) значительно меньше оптимального. Константа обмена кальция близка к оптимальной для сульфоугля $1.4\left(\mathrm{~cm}^{3} / \mathrm{cm}^{3}\right)^{1 / 2}$, а для КУ-2 $2.5\left(\mathrm{~cm}^{3} / \mathrm{cm}^{3}\right)^{1 / 2}$ существенно выше оптимальной, что объясняет большие расходы на регенерацию катионита КУ-2 по сравнению с сульфоуглем. На рис.1

Комарова и др. / Сорбционные и хроматографические процессы. 2017. Т. 17. № 6 
приведены линии уровня критерия оптимальности (расхода реагента в условных единицах) для катионита при изменении констант обмена натрия и кальция [20].

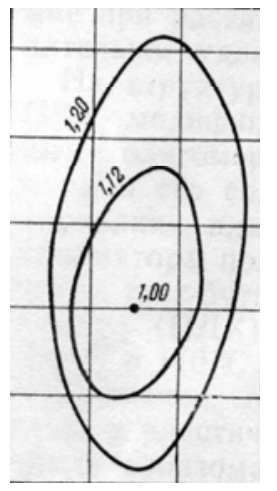

Рис. 1 Линии уровня критерия оптимальности при изменении констант обмена катионита

Постановке задачи оптимизации и ее решению способствовало обстоятельное знакомство с практикой водоподготовки в проектных, наладочных и эксплуатационных организациях, участие в отраслевых конференциях в нашей стране и за рубежом. Так, в лаборатории сорбционных методов под руководством М.М. Сенявина и при его непосредственном участии проводились совместные работы с наладочными (Союзтехэнерго), проектными (Теплоэлектропроект, Харьковское отделение Теплоэлектропроекта, ВНИИПИЭТ), научно-исследовательскими (МЭИ, ВТИ)) и эксплуатационными предприятиями (химслужбы Волгоградэнерго и Ростовэнерго, Волгоградская ТЭЦ-2, Новочеркасская ГРЭС, Ленинградская АЭС). M.M. Сенявин с сотрудниками принимал участия в отраслевых конференциях, совещаниях в министерстве энергетики, госкомитете по науке и технике, а также в совещаниях по ионному обмену и водоподготовке, организованными зарубежными фирмами. М.М. Сенявин сделал в 1988 году доклад на техническом совете Минэнерго «Расчет основных технологических характеристик и оптимизация промышленных ВПУ на основе математических моделей ионообменных процессов». В 1979 году М.М. Сенявин организовал конференцию по ионному обмену с международным участием, на которой был сделан доклад И.В.Комаровой,

M.М. Сенявина [17], в котором было показано, что оптимальные решения зависят от направленности ионообменного процесса. В случае очистки растворов оптимальными условиями являются малые скорости потока и большая длина слоя ионита, а при извлечении ценных или вредных компонентов необходимо проводить процесс при больших скоростях.

M.М. Сенявин считал необходимым ознакомить начальников химических цехов водоподготовительных установок с основами теории ионного обмена. С этой целью им были организованы курсы, для которых была составлена программа, подготовлено пособие по теории и практике ионного обмена. В течение месяца М.М. Сенявин и сотрудники лаборатории читали лекции и проводили практические занятия. В конце занятий слушатели писали рефераты.

На основе разработанных методов расчета и оптимизации процесса ионообменной деионизации воды совместно с МИТХТ им. М.В. Ломоносова были выполнены работы по расчету оптимальных режимов подготовки воды для котлов высокого давления на Волгоградской ТЭЦ-2.

По инициативе начальника РЭУ Волгоградэнерго была проведена работа по моделированию и оптимизации промышленного фильтра. С целью выявления возможности использования математической модели для расчета промышленных 
фильтров под руководством М.М. Сенявина была составлена программа работ, которая была согласована с главным инженером ТЭЦ-2 и начальником РЭУ Волгоградэнерго. Работа проводилась на Н-катионированном фильтре первой ступени Волгоградской ТЭЦ-2. Фильтр был подготовлен к экспериментам сотрудниками ТЭЦ.

Для проведения эксперимента была сформирована бригада, состоящая из сотрудников ГЕОХИ, МИТХТ, Волгоградэнерго и ТЭЦ-2. В процессе экспериментов, которые продолжались в течение месяца, было проведено 4 серии опытов. Был выполнен чрезвычайно большой объем аналитического контроля. Работа была непрерывной, технологический режим осуществлялся персоналом цеха. В экспериментах для изучения гидродинамики процесса в промышленном фильтре отбирались пробы в 26 точках фильтра с интервалом 5 минут во время регенерации и отмывки и 15-20 минут во время рабочего цикла. Каждую отобранную пробу анализировали на 5 компонентов: водород, натрий, калий, магний и кальций.

Марк Моисеевич приехал в Волгоград, чтобы принять участие в первом промышленном сорбционном эксперименте. Для участников работы было очень важно внимание М.М. Сенявина к их работе. Марк Моисеевич организовал экскурсию по всем цехам ТЭЦ, чтобы сотрудники видели не только химический цех, в котором они работали, но и все подразделения станции и процесс выработки тепла и электроэнергии. Марк Моисеевич принял участие в проведении эксперимента в ночную смену и даже лично грузил АН-31 в фильтр до прихода слесарей, чтобы обеспечить фронт работ он также участвовал в обработке данных и их обсуждении. Для работников химического цеха М.М. сделал сообщение о преимуществах противоточной регенерации. В опыте, который был проведен с М.М. Сенявиным, была сделана попытка подачи кислоты в фильтр и его отмывки снизу вверх. Для такой работы обычная обвязка фильтра не была приспособлена, поэтому схема была усложнена за счет включения в работу находящегося в резерве пустого фильтра. К сожалению, из-за большого объема резервного фильтра полностью реализовать противоточную регенерацию не удалось.

В результате проведенных экспериментов была показана адекватность математической модели процессу очистки на катионите в промышленном фильтре [29]. В этом эксперименте были выявлены технологические особенности работы промышленного фильтра: переменная концентрация кислоты на входе в слой ионита в процессе регенерации за счет наличия большого объема воды над слоем катионита, наличие взрыхления ионита, приводящему к изменению распределения катионов по слою катионита перед регенерацией, отмывка катионита после регенерации водой, поступающей на очистку, приводящая к частичной отработке слоя катионита.

Эти факторы были рассмотрены подробно при следующем промышленном эксперименте, проведенном на Новочеркасской ГРЭС совместно с Ростовэнерго. В математическое описание процесса включена модель взрыхления, отмывки и изменение концентрации на входе в слой ионита за счет наличия большого объема раствора над слоем ионита, что было учтено при оптимизации промышленных фильтров.

В совместной работе с Союзтехэнерго проведена классификация природных вод и типовых схем обессоливания воды, а также показана зависимость оптимальных условий процесса от состава исходной воды и глубины очистки, что в дальнейшем позволило находить оптимальную глубину очистки между ступенями при оптимизации технологической схемы.

Трудами М.М. Сенявина с сотрудниками было показано, что обоснованный выбор технологической схемы, включающей оптимальное оборудование и осуществляющей проведение процесса при оптимальных режимах в зависимости от состава

Комарова и др. / Сорбционные и хроматографические процессы. 2017. Т. 17. № 6 
исходной воды и требований к глубине очистки, может быть выполнен только на основе комплексного учета всех параметров, влияющих на процесс. Целесообразность поиска оптимальных режимов на основе детерминированных математических моделей как на стадии эксплуатации, так и на стадии проектирования необходима при оптимизации работы одного фильтра, а особенно при оптимизации схемы водоподготовки, когда возрастает число взаимосвязанных параметров, влияющих на процесс.

Метод расчета и оптимизации был применен к выбору оптимальных условий очистки конденсата АЭС. Работа была проведена с сотрудниками НИИПИЭТ, в результате которой было рассчитано и подтверждено экспериментально оптимальное соотношение катионита и анионита в смешанном слое [24,28 ].

М.M. Сенявин руководил работой по заданию ИМБП по определению оптимального соотношения катионита, анионита и угля , отвечающего одновременному проскоку ацетата аммония и этилового спирта в схеме очистки конденсата атмосферной влаги. Рассчитано и экспериментально подтверждено, что при оптимальном соотношении сорбентов продолжительность работы схемы можно увеличить до 66 часов при общей высоте слоя 93см [22].

Для определения коэффициентов математических моделей и проверки адекватности моделей реальным процессам по инициативе М.М. Сенявина совместно с НПО «Химавтоматика» создана автоматизированная система исследований сорбционных процессов (АСНИ ГЕОХИ) [26].

Автоматизированная система представляет собой программно-технический комплекс, включающий три сорбционных стенда, отличающихся методом измерения концентрации исследуемого иона, программируемый контроллер, стойку управления с блоками коммутации и преобразования сигналов, поступающих от стендов к контроллеру, а также персональный компьютер.

Технологическая схема стенда состоит из колонки, заполненной исследуемым сорбентом, емкостей, системы пневматической подачи растворов из емкостей в колонку, системы измерения и регулирования скорости потока через колонку, а также системы измерения концентрации целевого компонента на входе и выходе из колонки. Разработанный оригинальный пакет программ для персонального компьютера обеспечивает обмен данными между контроллером и компьютером, поддерживает диалоговый режим в процессе подготовки и проведения экспериментов, а также осуществляет сбор, накопление и обработку получаемых на стендах выходных кривых сорбционного процесса и запись результатов в банк данных.

Основные параметры математической модели, а именно равновесные и кинетические характеристики, определяются решением обратных задач по выходным кривым, получаемым на автоматизированном стенде АСНИ-ГЕОХИ, константы обмена анионов слабых кислот и константы ионизации слабоосновных анионитов - по специально разработанным методикам [ 13,15].

В результате была выработана методология решения технологических ионообменных задач методом математического моделирования процесса и его оптимизации

Методология решения ионообменной задачи, представленная на рис.2, отражает основные этапы исследования: разработка математической модели, экспериментальное определение коэффициентов модели и создание банка данных сорбентов, расчет и оптимизация процесса. В настоящее время в лаборатории сорбционных методов работы по моделированию и оптимизации ионообменных процессов продолжают развиваться [31].

Комарова и др. / Сорбционные и хроматографические процессы. 2017. Т. 17. № 6 


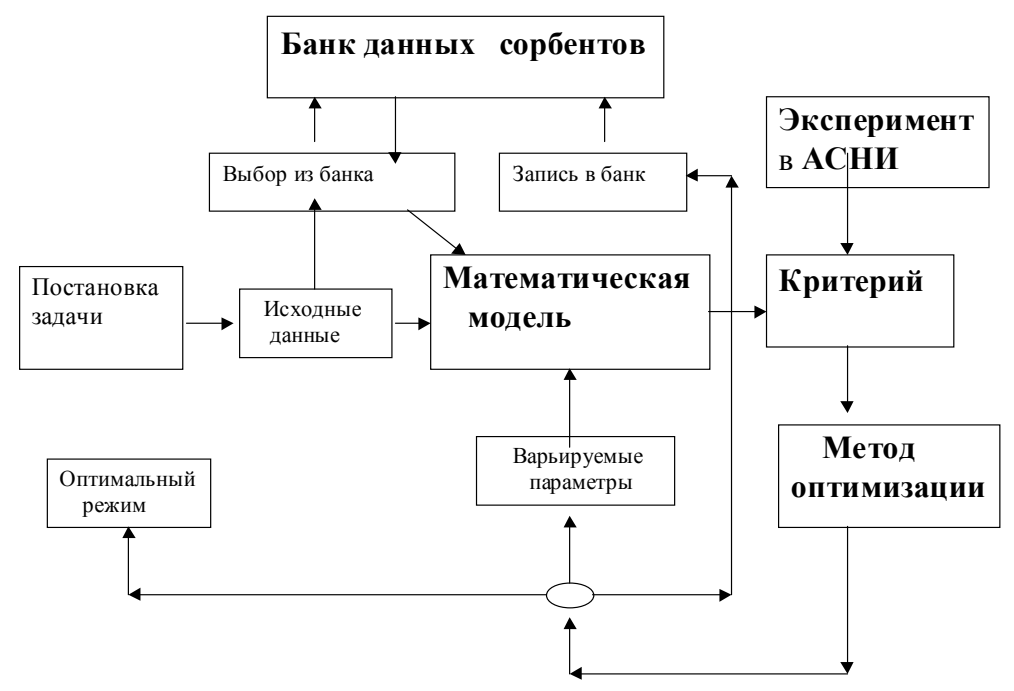

Рис. 2. Схема решения технологической задачи водоподготовки

\section{Заключение}

В лаборатории сорбционных методов под руководством М.М. Сенявина были решены следующие задачи оптимизации ионообменных процессов на основе математического моделирования: Разработаны адекватные математические модели процессов обессоливания воды ТЭС и очистки конденсата АЭС на лабораторных, укрупненных и промышленных установках.

Для накопления данных по коэффициентам математической модели и проверки ее адекватности создана автоматизированная система исследования АСНИГЕОХИ. Создан банк данных по коэффициентам математических моделей. Разработаны программы расчета и оптимизации ионообменных фильтров при различных схемах регенерации на основе математических моделей отдельных стадий процесса.

На основе математической модели рассчитаны Атласы технологических зависимостей для отечественных ионитов, по объему информации превосходящие каталоги технологических зависимостей зарубежных фирм-производителей ионитов. Разработаны программы расчета и оптимизации технологических схем водоподготовки. Проведен расчет режимов работы ряда ионообменных установок по обессоливанию и умягчению воды на стадии проектирования, наладки и эксплуатации. Результаты переданы в Союзтехэнерго, Узэнерго, Волгоградэнерго.

\section{Список литературы}

1. Сенявин М.М. // Ионный обмен и его применение. М. Академия наук СССР. 1959. C.84-126

2. Сенявин М.М. // Ионный обмен и его применение. М. Академия наук. 1959. С.127222

3 Сенявин М.М., Рубинштейн Р.Н., Веницианов Е.В., Галкина Н.К. и др. Основы расчета и оптимизачии ионообменных прочессов. М. Наука. 1972. С. 174.

4 Сенявин М.М., Рубинштейн Р.Н., Комарова И.В., Смагин В.Н. и др. Теоретические основы деминерализаиии пресных вод. М.Наука. 1975. 325 с.
5. Сенявин М.М. Ионный обмен в технологии и анализе неорганических веществ. М. Химия. 1980. $271 \mathrm{c.}$

6. Веницианов Е.В., Галкина Н.К., Ипполитова О.Д., Махалов Е.М. // Ионный обмен. М. Наука. 1981. С. 137-151

7. Галкина Н.К., Рубинштейн Р.Н., Сенявин М.М. // Доклады Академии Наук СССР. 1961. T. 137. № 5.C.1144-1146

8. Галкина Н.К., Сенявин М.М. // Журнал физической химии. 1972. Т. 46. С. 1205-1209.

9. Галкина Н.К., .Комарова И.В., Рубинштейн Р.Н., Сенявин М.М. // Журнал физической химии. 1973. Т. 47. № 1. С. 124. 
10. Галкина Н.К., Сенявин М.М., Ипполитова О.Д.,. Колотилина Н.К. // Журнал физической химии. 1983. Т. 57. № 9. С. 2319-2322.

11 Галкина Н.К., Сенявин М.М., Ипполитова О.Д.,. Колотилина Н.К. // Журнал физической химии. 1983. Т. 57. № 9. С. 2316-2319.

12. Галкина Н.К., Сенявин М.М., Ипполитова О.Д., Колотилина Н.К. // Химия и mехнология воды. 1984. Т. 6. вып. 3. С. 200-204.

13. .Колотилтна Н.К., Галкина Н.К., Сенявин М.М. // Журнал физической химии. 1984. T. 58. № 9. C. 2277-2280.

14. Галкина Н.К., Сенявин М.М., Ипполитова О.Д, Колотилина Н.К. // Журнал физической химии. 1984. Т. 58. № 6. С. 1506-1509.

15. Галкина Н.К., Сенявин М.М., Жигулева Т.И. // Журнал физической химии. 1984. Т. 58. № 9. C. 2268-2271.

16. .Галкина Н.К., Сенявин М.М., Веницианов Е.В, .Колотилтна Н.К. и др. // Журнал физической химии. 1987. Т. 61. № 4. С. 10471052.

17.Комарова И.В., Сенявин М.М. // Ионный обмен. М. Наука. 1981. С. 167-182.

18.Комарова И.В., Рубинштейн Р.Н., Сенявин М.М. // Журнал физической химии 1972.T. 56. C. 2834-2837.

19. Сенявин М.М., Галкина Н.К., Комарова И.В. // Теплоэнергетика 1980. №6. С. 2-7.

20. Комарова И.В., Сенявин М.М., Махалов Е.М. // Журнал «Пластические массы». 1981. № 1. C. 27-30.

21. Махалов Е.М., Свечинский В.Б., Комарова И.В., Сенявин М.М. // Химия и технология воды. 1982. Т. 4. № 5. С.403-407.

\section{References}

1. Senjavin M.M., Ionnyj obmen i ego primenenie, M. Akademija nauk SSSR, 1959, pp. 84126.

2. Senjavin M.M., Ionnyj obmen i ego primenenie, M., Akademija nauk, 1959, pp. 127-222.

3. Senjavin M.M., Rubinshtejn R.N., Venicianov E.V., Galkina N.K. et al., Osnovy rascheta i optimizacii ionoobmennyh processov, M., Nauka, 1972, pp. 174.

4. Senjavin M.M., Rubinshtejn R.N., Komarova I.V., Smagin V.N. et al., Teoreticheskie osnovy demineralizacii presnyh vod, M., Nauka, $1975,325 \mathrm{p}$.

5. Senjavin M.M., Ionnyj obmen v tehnologii i analize neorganicheskih veshhestv, M., Himija, 1980, $271 \mathrm{p}$.
22. Золотарева Е.А., Колосова Г.М., Гайдадымов В.Б., Комарова И.В. и др. // Химия и технология воды. 1982. Т. 4. № 3. С. 260-263.

23. Гвоздев В.Ф., Шептовецкая К.И., Махалов Е.М., Комарова И.В. и др. // Теплоэнергетика. 1982. № 9. С. .2-6.

24. Сенявин М.М., Комарова И.В., Галкина Н.К., Веницианов Е.В. и др. // Bonpocы атомной науки и техники Серия "Физика и техника ядерных реакторов. М. ЦНИИАТОМИНФОРМ. 1986. № 3. С. 25-27.

25. Сенявин М.М., Галкина Н.К., Комарова И.В. // Химия и технология воды. 1986. Т. 8. № 3. С. 15-19.

26. Аргин М.А., Комарова И.В., Сенявин М.М., Штраль И.Я. и др. // Химия и технология воды. 1990. Т. 12. № 4. С. 378-381.

27.Комарова И.В., Галкина Н.К., Махалов Е.М., Ипполитова О.Д. и др. // Теория $u$ практика сорбиионных проиессов. 1989. № 20. C. $30-41$.

28.Аргин М.А., Комарова И.В., Галкина Н.К., Закова И.М. и др. //Атомная энергия. 1985. Т. 59. С. 137-138.

29. Закова И.М., Комарова И.В., Одинцов К.Ю., Лебедев В.Ю.. // Теплоэнергетика. 1983. № 7. C. 13-16.

30..Комарова И.В., Галкина Н.К., Никашина В.А., Анфилов Б.Г. // Сорбционные и хроматографические прочессы. 2001. Т. 1. № 4. C. 606-612.

31.Комарова И.В., Галкина Н.К., Шептовецкая К.И, Анфилов Б.Г. и др. // Сорбционные и хроматографические проиессы. 2007. T. 7. № 2. C. 187-196.

6. Venicianov E.V., Galkina N.K., Ippolitova O.D., Mahalov E.M., Ionnyj obmen, M., Nauka, 1981, pp. 137-151.

7. Galkina N.K., Rubinshtejn R.N., Senjavin M.M., Doklady Akademii Nauk SSSR, 1961, Vol. 137,No 5, pp. 1144-1146.

8. Galkina N.K., Senjavin M.M., Zhurnal fizicheskoj khimii, 1972, Vol. 46, pp. 1205-1209.,

9. Galkina N.K., .Komarova I.V., Rubinshtejn R.N., Senjavin M.M., Zhurnal fizicheskoj khimii, 1973, Vol. 47, No 1, pp.124.

10. Galkina N.K., Senjavin M.M., Ippolitova O.D., Kolotiltna N.K., Zhurnal fizicheskoj khimii, 1983, Vol. 57, No 9, pp. 2319-2322. 
11 Galkina N.K., Senjavin M.M., Ippolitova O.D., Kolotiltna N.K., Zhurnal fizicheskoj khimii, 1983, Vol. 57, No 9, pp. 2316-2319.

12. Galkina N.K., Senjavin M.M., Ippolitova O.D., Kolotilina N.K., Himija i tehnologija vo$d y$, 1984, Vol. 6, No 3, pp. 200-204.

13. .Kolotiltna N.K., Galkina N.K., Senjavin M.M., Zhurnal fizicheskoj himii, 1984, Vol 58, No 9, pp. 2277-2280.

14. Galkina N.K., Senjavin M.M., Ippolitova O.D., Kolotiltna N.K., Zhurnal fizicheskoj khimii, 1984, Vol. 58, No 6, pp. 1506-1509.

15. Galkina N.K., Senjavin M.M, Zhiguleva T.I., Zhurnal fizicheskoj khimii, 1984, Vol. 58, No 9, pp. 2268-2271.

16. .Galkina N.K,.Senjavin M.M,.Venicianov E.V, .Kolotiltna N.K. et al., Zhurnal fizicheskoj khimii, 1987, Vol. 61, No 4, pp. 1047-1052.

17.Komarova I.V., Senjavin M.M., Ionnyj obmen, M., Nauka, 1981, pp. 167-182.

18.Komarova I.V., Rubinshtejn R.N., Senjavin M.M., Zhurnal fizicheskoj khimii, 1972, Vol. 56, pp. 2834-2837.

19. Senjavin M.M., Galkina N.K., Komarova I.V., Teplojenergetika, 1980, No 6, pp .2-7.

20. Komarova I.V., Senjavin M.M., Makhalov E.M., Zhurnal «Plasticheskie massy», 1981, No 1, pp. 27-30.

21. Makhalov E.M., Svechinskij V.B., Komarova I.V., Senjavin M.M., Himija i tehnologija vody, 1982, Vol. 4, No 5, pp. 403-407.

22. Zolotareva E.A., Kolosova G.M., Gajdadymov V.B., Komarova I.V. et al., Himija i tehnologija vody, 1982, Vol. 4, No 3, pp. 260-263.

Комарова Ирина Владимировна к.Х.н., старший научный сотрудник, лаборатория сорбционных методов, ГЕОХИ РАН

Галкина Надежда Константиновна - к.Х.н., старший научный сотрудник, лаборатория сорбционных методов, ГЕОХИ РАН
23. Gvozdev V.F., Sheptoveckaja K.I., Mahalov E.M., Komarova I.V., et al., Teplojenergeti$k a, 1982$, No 9, pp. 2-6.

24. Senjavin M.M., Komarova I.V., Galkina N.K., Venicianov E.V. et al., Voprosy atomnoj nauki i tehniki Serija «Fizika i tehnika jadernyh reaktorov», M., CNIIATOMINFORM, 1986, No 3, pp. 25-27.

25. Senjavin M.M., Galkina N.K., Komarova I.V., Himija i tehnologija vody, 1986, Vol. 8, No 3, pp. 15-19.

26. Argin M.A., Komarova I.V., Senjavin M.M., Shtral' I.Ja., et al., Himija i tehnologija vody, 1990, Vol. 12, No 4, pp. 378-381.

27.Komarova I.V., Galkina N.K., Makhalov E.M., Ippolitova O.D. et al., Teorija i praktika sorbtsionnykh protsessov, 1989, No 20, pp. 3041.

28.Argin M.A., Komarova I.V., Galkina N.K.,Zakova I.M. et al., Atomnaja jenergija, 1985, Vol. 59, pp. 137-138.

29. Zakova I.M., Komarova I.V., Odincov K.Ju., Lebedev V.Ju., Teplojenergetika, 1983, No 7, pp. 13-16.

30..Komarova I.V., Galkina N.K., Nikashina V.A., Anfilov B.G., Sorbtscionnye i khromatograficheskie protsessy, 2001, Vol. 1, No 4, pp. 606-612.

31.Komarova I.V., Galkina N.K., Sheptoveckaja K.I, Anfilov B.G. et al., Sorbtscionnye $i$ khromatograficheskie protsessy, 2007, Vol. 7, No 2, pp. 187-196.

Komarova Irina V. - Ph.D. (Chem.), Senior researcher, Lab of Sorption Methods, GEOKHI RAS

Galkina Nadezda K. - Ph.D. (Chem.), Senior researcher, Lab. of Sorption Methods, GEOKHI RAS 